\title{
Role of Multidetector Computed Tomography in Renal Artery Variations
}

\author{
Karthik Marpalli Vasudeva ${ }^{1}$, Jini Pullalathu Abraham ${ }^{2}$ \\ ${ }^{1}$ Assistant Professor, Department of Radiodiagnosis, A.J. Institute of Medical Sciences and Research Centre, Mangalore, \\ Karnataka, ${ }^{2}$ Senior Resident, Department of Radiodiagnosis, A.J. Institute of Medical Sciences and Research Centre, \\ Mangalore, Karnataka, India
}

Corresponding author: Karthik Marpalli Vasudeva, Assistant Professor, Department of Radiodiagnosis, A.J. Institute of Medical Sciences and Research Centre, Mangalore, Karnataka, India

DOI: http://dx.doi.org/10.21276/ijcmsr.2020.5.2.20

How to cite this article: Karthik Marpalli Vasudeva, Jini Pullalathu Abraham. Role of multidetector computed tomography in renal artery variations. International Journal of Contemporary Medicine Surgery and Radiology. 2020;5(2):B81-B83.

\section{A B S T R A C T}

Introduction: There are many variations in renal arterial anatomy. These variations can show ethnic and racial differences These are particularly important in surgical planning and transplantation. Preoperative knowledge of variant anatomy leads to lesser complications during surgery. The purpose of this study was to see the prevalence of renal arterial variation in our study population.

Material and methods: This was a prospective study done in a tertiary care hospital in southern India and approved by the Ethical board of the institution. 200 consecutive patients from January 2019 to December 2019 undergoing MDCT angiography were included in the study. Both males and females were included in the study between the ages of 5 to 70 years. Multidetector Computed tomography was performed and the collected images were then analyzed for the number of main renal arteries, accessory renal arteries, polar arteries, and early bifurcation.

Results: A total of 200 patients were evaluated out of which 115(57.5)\% were males and 85(42.5\%) were females. 83 cases $(41.5 \%)$ showed variations in the bifurcation and branching of the renal arteries. Out of this $41.5 \%, 68.6 \%$ were accessory renal arteries and $31.3 \%$ were variations in early branching.

Conclusion: This study concludes that variation in the renal arterial anatomy is common, occurring in $41.5 \%$ of our study population with the majority being accessory arteries and a small proportion being early divisions.

Keywords: Renal Artery Variations, Accessory Artery, Polar Artery, Multidetector Computed Tomography,

\section{INTRODUCTION}

Renal arteries arise from the lateral aspect of the abdominal aorta just beneath the origin of the superior mesenteric artery. The majority of the time renal arteries on each side are single. ${ }^{1}$ There are many variations in renal arterial anatomy. ${ }^{2-4}$ These variations can show ethnic and racial differences. ${ }^{5}$ These are particularly important in surgical planning and transplantation. Preoperative knowledge of variant anatomy leads to lesser complications during surgery. Multidetector computed (MDCT) angiography is the best non-invasive modality for the evaluation of renal vasculature. Main indications for MDCT are renal trauma, renal tumors, arteriovenous malformations, and fistulas, evaluation for renal donors and as a workup to rule out renovascular hypertension. The main drawbacks of MDCT include ionizing radiation and the use of iodinated contrast.

The purpose of this study was to see the prevalence of renal arterial variation in our study population.

\section{MATERIAL AND METHODS}

This was a prospective study done in a tertiary care hospital in southern India and approved by the Ethical board of the institution. 200 consecutive patients from January 2019 to December 2019 undergoing MDCT angiography were included in the study. Both males and females were included in the study between the ages of 5 to 70 years. Patients with a history of renal surgeries and trauma, those who didn't give consent, patients who had contraindications for MDCT and those suffering from Takayasu arteritis were excluded from the study group.

MDCT angiography was performed using 128 slice MDCT (Siemens). The area covered was from diaphragm to the symphysis pubis. The patient was positioned supine and 100 $\mathrm{ml}$ of non-ionic contrast medium was injected at the rate of $4 \mathrm{ml} / \mathrm{sec}$ followed by saline flush through the antecubital vein with $18 \mathrm{G}$ cannula using a power injector. The time of delay was chosen using a bolus tracking method. The scan was automatically started once a threshold of $150 \mathrm{HU}$ was reached. Source images were transferred to the workstation and the post-processing was done.

The collected images were then analyzed for the number of main renal arteries, accessory renal arteries, polar arteries, 
and early bifurcation. The accessory renal artery was defined as an artery other than the main renal artery supplying the kidney. ${ }^{6}$ The polar artery is one that directly enters the pole and not through the hila. ${ }^{7}$ If the main renal artery had its first segmental branch within $1 \mathrm{~cm}$ from its aortic origin it was considered early division. ${ }^{8}$ This prospective study was approved by the institutional ethics committee.

\section{STATISTICAL ANALYSIS}

Descriptive statistics were applied, absolute and relative frequencies.

\section{RESULTS}

A total of 200 patients were evaluated out of which $115(57.5) \%$ were males and 85(42.5\%) were females. 83 cases $(41.5 \%)$ showed variations in the bifurcation and branching of the renal arteries. Out of this $41.5 \%, 68.6 \%$ were accessory renal arteries and $31.3 \%$ were variations in early branching. Among the $14(7 \%)$ right-sided accessory renal artery patients, $9(64.2 \%)$ were hilar and 5(35.7\%) were polar arteries, and of the 28 (14\%) left-sided accessory renal artery patients, 18 (64.2\%) were hilar and 8(28.5\%) were polar arteries.2 $(7 \%)$ patients among the left-sided accessory renal arteries had both hilar and polar arteries. There were $15(7.5 \%)$ patients having accessory renal arteries on both sides with purely hilar arteries bilaterally in $7(46.66 \%)$ of them and purely polar arteries in 6(40\%) of them and mixed

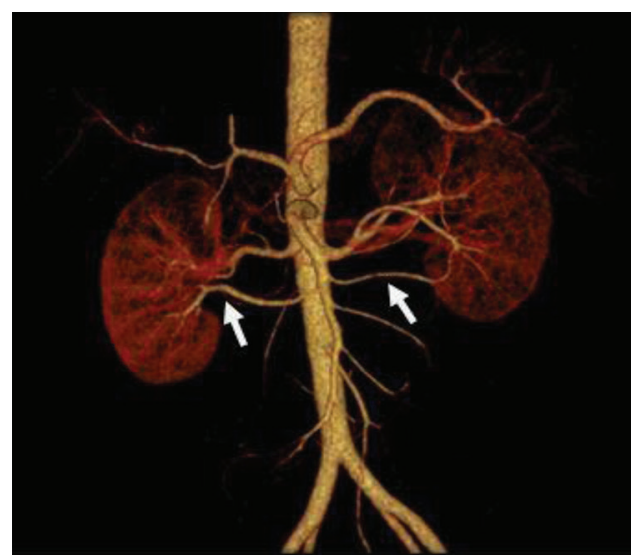

Figure-1: Coronal VRT images showing right and left lower accessory renal arteries (arrows).

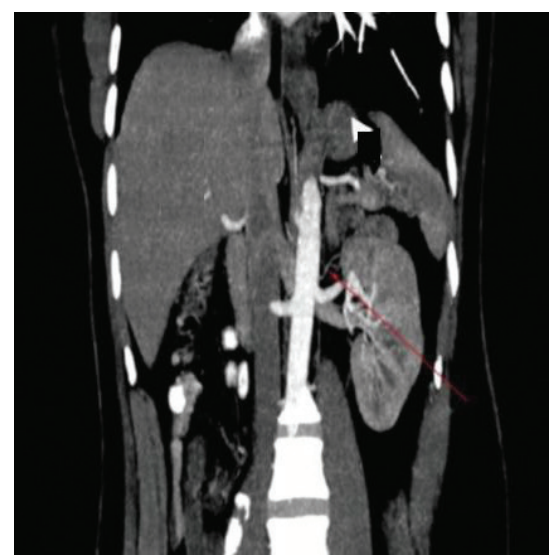

Figure-2: Coronal MIP image showing left polar renal artery (red arrow) supplying the left upper pole.

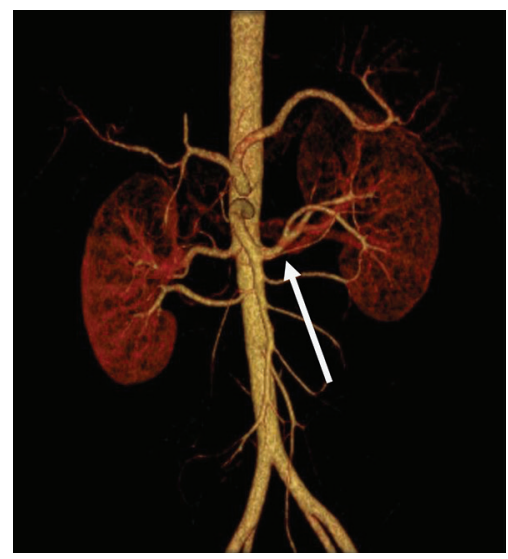

Figure-3: Coronal VRT images showing early bifurcation of the left renal artery (arrow)

variation in $2(13.3 \%)$ of them. In our study population, early bifurcation was seen in 26 (13\%) patients out of whom early bifurcation of the right renal artery was seen in $8(30.7 \%)$ patients and of the left renal artery was seen in 18 (69.2\%) patients.

\section{DISCUSSION}

In our study population, we found renal arterial variation in $41.5 \%$ of our patients. $28.5 \%$ of our patients had accessory renal arteries and $13 \%$ had an early division. This is similar to a study by Munnusamy et al who found earlier division in $12 \%$ and accessory renal arteries in $38 \% .^{8}$ As compared to this, Gumus et al had a higher number of earlier divisions (27\%) and a lower number of accessory renal arteries (27\%) in their study. ${ }^{6}$ Among the $28.5 \%(57)$ accessory renal arteries in our study, 7\%(14) were right-sided renal arteries (Fig1), 14\%(28) were left-sided and 7.5\%(15) were bilateral. This was different from the Munnuswamy et al study which had an incidence of $13 \%$ on each side and $12 \%$ bilaterally. ${ }^{8}$ This could be because of regional variation. The significance of this finding is in renal transplant surgeries where surgeons usually utilize kidneys with a single renal artery as they are less complicated surgeries and there is also a lesser risk of thrombosis of the arteries. ${ }^{9}$ However, in another study by Hsu et al, the presence of more than one renal artery did not have increased complications such as blood loss in the donor nor had much effect on one-year graft survival if the surgeons knew about the anatomy beforehand. ${ }^{10}$ In our study, all the accessory arteries originated from the aorta. This finding is crucial to mention as laparoscopic surgery has a limited field of view and hence other arteries may not be accessible.

Out of 7\%(14) right-sided accessory renal arteries in our study we found $64.2 \%(9)$ were hilar and $35.7 \%(5)$ were polar (Fig 2). This was similar to the study done by Swarna et al who found among the right-sided accessory arteries 58.5\% were hilar arteries and $41.5 \%$ were polar arteries. ${ }^{11}$ Among the $14 \%$ (28) left-sided accessory arteries in our study 64.2\%(18) were purely hilar arteries and 28.5\%(8) were purely polar arteries. 7\%(2) patients had a mixture of both accessory and polar arteries on the left side. As compared to this, among the left-sided accessory renal arteries in Swarna et al study $61.8 \%$ were hilar arteries and $38.2 \%$ were polar arteries. ${ }^{11}$

In our study population, early bifurcation was seen in 26 
(13\%) patients out of whom early bifurcation of the right renal artery was seen in $8(30.7 \%)$ patients and of the left renal artery was seen in $18(69.2 \%)$ patients (Fig-3). The study by Munnuswamy et al similarly had a similar proportion of $13 \%$ early segmentary bifurcation with right-sided early division in $5 \%$ and left-sided in $7 \% .^{8} \mathrm{~A}$ study by Ozkan et al showed the proportion of early segmental division of renal arteries to be $8 \%$ in their study. ${ }^{12}$ These early division cases with a short pedicle are not suitable for anastomosis in renal transplant surgeries. ${ }^{13}$

\section{CONCLUSION}

This study concludes that variation in the renal arterial anatomy is common, occurring in $41.5 \%$ of our study population with the majority being accessory arteries and a small proportion being early divisions.

\section{REFERENCES}

1. Susan Standring. Gray's Anatomy. Churchill Livingstone. 2008;40(1):1183

2. Shakeri AB, Tubbs RS, Shoja MM, Pezeshk P, Farahani RM, Khaki AA, et al. Bipolar supernumerary renal artery. Surg Radiol Anat. 2007;29(1):89-92.

3. Rao M, Bhat SM, Venkataramana V, Deepthinath R, Bolla SR. Bilateral prehilar multiple branching of renal arteries: a case report and literature review. Kathmandu University Medical Journal (KUMJ). 2006;4(3):345-48.

4. Satyapal KS,Haffejee AA, Singh B, Ramsaroop L, Robbs JV, Kalideen JM. Additional renal arteries incidence and morphometry. Surg Radiol Anat. 2001;23(1):33-38

5. Kadir S. Kidneys. In: Kadir S, ed. Atlas of normal and variant angiographic anatomy.Philadelphia: W.B. Saunders Company, 1991; 387-429

6. Gumus H, Brdal Ozdemir E, Cetincakmak ML, Tekbas G, Ekici, Onder H, et al. Variations of renal artery in 820 patients using 64-detector CT-Angiography. Renal Failure. 2012;34(4):286-90.

7. Türkvatan A, Akinci S, Yildiz S, Olçer T, Cumhur T. MDCT for preoperative evaluation of vascular anatomy in living renal donors. Surg Radiol Anat 2009;31(2):227-35.

8. Munnusamy K, Kasirajan SP, Gurusamy K, Raghunath G, Bolshetty SL, Chakrabarti S, et al. Variations in Branching Pattern of Renal Artery in Kidney Donors Using CT Angiography. J Clin Diagn Res. 2016;10(3): AC01-3.

9. Sebastia C, Peril L, Salvador R, Buñesch L, Revuelta I, Alcaraz A, et al. Multidetector CT of living renal donors: lessons learned from surgeons. Radiographics 2010;30(6):1875-90.

10. Hsu TH, Su Li, Ratner LE, Trock BJ, Kavoussi LR. Impact of renal artery multiplicity on outcomes of renal donors and recipients in laparoscopic donor nephrectomy. Urology. 2003;61(2):323-27.

11. Swarna, Agarwal Y, Jain S, Chawla AS. Renal vasculature: Spectrum of anatomical variations and the significance from a surgeon's standpoint - Astrocyte; 2018:233-239.

12. Ozkan U, Oguzkurt L, Tercan F, Kizilkilic O, Koc $Z$, Koca N. Renal artery origins and variations: angiographic evaluation of 855 consecutive patients.
Diagn Interv Radiol. 2006;12(4):183-86.

13. Weld KJ, Bhayani SB, Belani J, Ames CD, Hruby G, Landman J. Extrarenal vascular anatomy of kidney: assessment of variations and their relevance to partial nephrectomy. Urology. 2005;66(5):985-89.

\section{Source of Support: Nil; Conflict of Interest: None}

Submitted: 18-04-2020; Accepted: 17-05-2020; Published online: 26-06-2020 